\title{
Outcome after antenatal diagnosis of upper urinary tract dilatation by ultrasonography
}

\author{
T R GUNN, ${ }^{*}$ J D MORA, ${ }^{*}$ AND P PEASE $\dagger$
}

*St Helens Hospital, Department of Paediatrics and †Department of Paediatric Surgery, School of Medicine, University of Auckland, New Zealand

SUMmARY A prospective study was carried out during 1986 to find out the incidence of fetal renal tract anomalies in 3228 pregnant mothers delivered in one hospital. Ultrasound examination of the fetus was performed as part of the routine antenatal assessment at 16-20 weeks' gestation, and later examinations were done if there were obstetric indications. Fetuses with any degree of dilatation of the renal pelvis or other renal tract anomalies were followed up with serial ultrasound examinations in utero and then postnatally at 6 days and 6 weeks of age, or earlier if indicated.

No renal tract anomalies were detected before 28 weeks' gestation, but of 761 fetuses examined later, 62 had dilatation of the renal pelvis not associated with overdistended bladders, and one fetus was anephric. After birth 10 of these infants (16\%) were found to have pronounced renal tract abnormalities. Three who had associated serious congenital abnormalities died, five infants had obstruction of the pelviureteric junction, and two infants had vesicoureteric reflux. Antenatal ultrasonographic examination after 28 weeks identified pronounced renal tract abnormalities in asymptomatic infants with a frequency of $9 \cdot 2 / 1000$ births (seven of 761 ) thus permitting early treatment and reducing the incidence of late complications.

The development of ultrasound examination of the fetus has resulted in the identification of many fetal abnormalities. In particular, abnormalities of the fetal urinary tract are being recognised more often, as hydronephrotic and cystic lesions are easily seen on ultrasonography and oligohydramnios is an indication for maternal scanning. If serious fetal urinary tract abnormalities are diagnosed they are reliable indicators of urinary tract disease in the infant. ${ }^{1-7}$

In order to identify what proportion of minor abnormalities of the fetal renal pelvis progressed to pronounced hydronephrosis and renal tract disease in the postnatal period, we studied their occurrence and natural history. At this hospital ultrasound examinations are performed routinely on all pregnant women, usually at 16-20 weeks' gestation or on first presentation to the antenatal clinic, and later examinations are done if there are obstetric indications. All the infants included in this study were delivered at one obstetric hospital in the year 1986.

We report the outcome of patients with upper urinary tract dilatation not associated with an overdistended bladder that was diagnosed antenatally and in the absence of other renal lesions, such as cystic dysplasia.

\section{Patients and methods}

There were 62 patients in whom prenatal ultrasonographic diagnosis of unilateral or bilateral dilatation of the renal pelvis was made. All ultrasound examinations were performed with real time ultrasound equipment using a $3.5 \mathrm{MHz}$ transducer. The fetal anatomy was carefully screened by the staff radiologists. Measurements were taken of the biparietal diameter, the abdominal diameter, and the length of the fetal limbs. The kidneys and urinary bladder were localised and morphology and size were noted. The examination before 20 weeks' gestation was intended to assess gestational age and the presence of more than one fetus, and also to detect fetal malformations. Those women who presented late for booking were scanned at their first visit to the clinic. There were no further routine ultrasound examinations done, but late scans were done when clinically indicated to assess fetal growth and placental site, or for other obstetric reasons. 
Before 30 weeks' gestation collecting systems were seldom visible as more than echolucent slits; any that were more obvious were regarded as suspicious and were monitored by serial sonograms. A visible ureter was regarded as abnormal. After 30 weeks' gestation a visible ureter was still regarded as abnormal. Fluid clearly visible in a collecting system unilaterally was also considered abnormal and monitored by serial sonograms. Bilateral prominence of the collecting system was assessed subjectively. If the width of a collecting system measured in the anterior posterior diameter was similar to its length, abnormal dilatation was a possibility and follow up studies were done.

The maximum length of each collecting system was measured and recorded in an attempt to establish base line values. This method differs from other recently published studies in which the anterior posterior diameter was chosen. ${ }^{8-10}$ We chose the length because it is easier to measure, and is more likely to reflect abnormalities of the renal infundibula or calyces, or both. The amniotic fluid was evaluated qualitatively as polyhydramnios, normal, or oligohydramnios. In no case was either antenatal surgical intervention or premature induction of labour undertaken. When a urinary tract anomaly had been detected antenatally, the patients all had serial sonographic examinations either antenatally or postnatally. The same paediatrician examined all the infants after birth. Repeat ultrasound examinations were done at 6 days and at 6 weeks after delivery or earlier in infants in whom moderate or severe dilatation of the calyces had been seen prenatally. Micturating cystourethrograms and intravenous urograms were performed in 15 cases to establish the diagnosis, and surgical evaluation and correction were undertaken in three.

\section{Results}

From 1 January to 31 December 19863228 infants were born. A total of 4070 fetal ultrasound examinations were performed before 28 weeks' gestation, and an additional 761 fetal examinations were done after 28 weeks' gestation for obstetric reasons. No renal tract abnormalities were identified in the fetal ultrasound examinations before 28 weeks' gestation, even in those fetuses in which later scans showed urinary tract abnormalities. In the 761 fetal examinations done after 28 weeks' gestation there were 62 fetuses $(8 \%)$ in which unilateral or bilateral dilatation of the upper urinary tract was found. No fetuses had obstruction of the bladder neck on ultrasound examination. All the infants who had renal abnormalities on later evaluation were in the group in which the total length of the fetal renal collecting system was dilated to more than $15 \mathrm{~mm}$ before full term.

The antenatal ultrasonographic findings are compared with the postnatal diagnoses in table 1 . The postnatal ultrasound scans at the end of 6 weeks of life were normal in $\mathbf{4 0}$ of the infants. A further five infants were lost to follow up. The three infants who had antenatal diagnoses of renal tract malformations in association with other major congenital abnormalities all died. One fetus was anephric on scanning and Potter's syndrome was confirmed at necropsy. One fetus with bilateral hydronephrosis had congenital heart disease confirmed at necropsy, and one with hydronephrosis had trisomy 13.

Fifteen infants had persisting renal tract dilatations on postnatal ultrasound examination at 6 weeks of age, and so micturating cystourethrograms and intravenous urograms were performed (table 2). In eight of the 15 the examinations were normal, though three of the eight had large extrarenal pelvises, which are considered to be a variant of normal.

In seven of the 15 infants renal tract abnormalities were confirmed. There were two infants with grade

Table 1 Antenatal and postnatal ultrasonographic findings in 63 patients

\begin{tabular}{lcl}
\hline & Total No & No of deaths \\
\hline $\begin{array}{l}\text { Antenatal findings: } \\
\text { Absent kidneys } \\
\text { Dilatation of renal pelvis }\end{array}$ & 1 & \\
$\begin{array}{l}\text { Postnatal findings: } \\
\quad \text { Potter's syndrome }\end{array}$ & 62 & \\
$\begin{array}{l}\text { Hydronephrosis and trisomy 13 } \\
\text { Hydronephrosis and congenital } \\
\quad \text { heart disease }\end{array}$ & 1 & 1 \\
$\begin{array}{l}\text { Ultrasonography normal by } \\
\quad 6 \text { weeks of age }\end{array}$ & 1 & 1 \\
$\quad \begin{array}{l}\text { Ultrasonography abnormal at } \\
\quad 6 \text { weeks of age }\end{array}$ & 40 & 0 \\
Lost to follow up & 15 & 0 \\
\hline
\end{tabular}

Table 2 Results of micturating cystography and intravenous urography in 15 infants with dilatation of the renal pelvis persisting after 6 weeks of age

\begin{tabular}{|c|c|}
\hline Results & $\begin{array}{l}\text { No of } \\
\text { infants }\end{array}$ \\
\hline No abnormality & 8 \\
\hline $\begin{array}{l}\text { Unilateral obstruction of pelviureteric junction } \\
\text { corrected by pyeloplasty }\end{array}$ & 3 \\
\hline $\begin{array}{l}\text { Minor unilateral obstruction of pelvi } \\
\text { ureteric junction under observation }\end{array}$ & 2 \\
\hline Vesicoureteric reflux grade 2 or 3 & 2 \\
\hline
\end{tabular}


2 or 3 vesicoureteric reflux who were given long term antibiotic treatment. Five infants had obstructions of the pelviureteric junctions, and HinesAnderson pyeloplasties were performed in three with relief of the obstruction. Two with minor obstructions were still under observation at the time of writing and were on long term antibiotic treatment because of recurrent urinary tract infections. Thus 10 of the 63 fetuses that had renal tract anomalies identified by ultrasonography screening $(16 \%)$ had pronounced renal tract abnormalities in the neonatal period, three of which were associated with other lethal congenital malformations. We were able to identify seven fetuses with minor dilatation of the renal pelvises who had pronounced renal tract abnormalities that required postnatal treatment and that could not be diagnosed by clinical postnatal examination. This is an incidence of $9.2 /$ 1000 (seven of 761) fetuses scanned after 28 weeks' gestation.

\section{Discussion}

Early diagnosis of upper renal tract obstruction or reflux is unfortunately seldom possible from the clinical signs of a palpable abdominal mass, haematuria, or recurrent urinary tract infections, because these lesions are often symptomless until severe renal damage has occurred. The timing of the surgical correction is thought to be important in reducing chronic renal insufficiency, as the best results are achieved in infants operated on in the first year of life. ${ }^{11}$

We have analysed the efficacy of routine ultrasound screening for diagnosing fetal upper urinary tract dilatation after 28 weeks' gestation as part of the maternal antenatal evaluations. In the antenatal period we identified important renal tract abnormalities that could not be found by clinical examination of the newborn infant with a frequency of $9 \cdot 2 / 1000$ births. We also identified the infants with lethal congenital abnormalities in addition to renal abnormalities, who comprised $30 \%$ of the group. This is similar to the findings of Hobbins et al. . $^{2}$

In the early reports of the antenatal diagnosis of urinary tract abnormalities there was a marked bias towards severe cases ${ }^{5} 612$ and only a few cases were found to be normal in the postnatal period. Nicolini et al,,$^{13}$ however, reported a frequency of false positives of $43 \%$. Their series included a number of cases referred because of suspicious ultrasound findings. In our study of patients from the obstetric population of one hospital, the rate of disappearance of dilatation of the renal pelvis during antenatal or postnatal life was much higher $(83 \%)$. We have, however, followed up a group of fetuses identified mainly by minor degrees of dilatation of the renal pelvis.

Arger et $a l^{10}$ reported that any fetus with a renal pelvis larger than $10 \mathrm{~mm}$ had pronounced hydronephrosis warranting close follow up. A morphologic classification of fetal urinary tract dilatation has been proposed by Grignon $e a^{8}$ who suggested that an anterior posterior diameter of the renal pelvis of less than $10 \mathrm{~mm}$ should be considered physiological as this disappeared in $97 \%$ of the infants in their study. Our study confirms these findings. We found that an abnormality was likely in those fetuses with dilated renal infundibula, or visible calyces, or both. The total length of the collecting system was greater than $15 \mathrm{~mm}$ before full term in all the infants who had renal abnormalities on follow up examination.

We found, however, that in several cases the degree of dilatation in the fetal period did not correlate with the chance of serious abnormality requiring surgical correction later. In some cases minor dilatation of the fetal renal pelvis progressed to severe obstruction requiring postnatal surgical correction, while in others serious dilatation resolved completely during the period of observation, either in utero or after birth. This is in agreement with the findings of others. ${ }^{9} 13$ Frequent antenatal and early and repeated postnatal ultrasonographic evaluations are therefore necessary.

The natural history of dilatation of the fetal renal pelvis is not yet completely understood. Fetal hydronephrosis without dilatation of the bladder seems to occur mainly after 28 weeks' gestation, as it was not diagnosed in any fetal examination before 28 weeks' gestation in our series. This may be due to a considerable increase in fetal production of urine from 27-32 weeks' gestation with correspondingly less increase in kidney size. ${ }^{1314}$

The incidence of upper urinary tract abnormalities requiring postnatal treatment was higher in our series than in earlier reports ${ }^{1315}$ and this may be because we followed up all those with even minor degrees of fetal dilatation of the renal pelvis. The most frequent cause of hydronephrosis was obstruction of the pelviureteric junction, and surgical correction was required in some of the infants in the first few months of life resulting in satisfactory renal function. Other infants with minor delay at the pelviureteric junction continue to be evaluated and long term antibiotic treatment for recurrent urinary tract infections is required.

Nicolini et $\mathrm{al}^{13}$ reported that mortality, morbidity, and renal damage were not associated with the time between prenatal diagnosis of hydronephrosis (when the bladder is normal) and operation (when this is performed in the neonatal period). They 
agreed with Berkowitz et al ${ }^{10}$ who did not recommend premature induction of labour or shunt placement in utero with its attendant risks. Antenatal operation should be considered only for severe bilateral obstruction of the upper urinary tractswhich is extremely rare - or for severe dilatation of a solitary kidney. Bilateral dysplastic kidneys follow complete obstruction early in development, and the fetus with this abnormality has a poor prognosis. ${ }^{16}$ The development of oligohydramnios seemed to be the most reliable indication of severe impairment. ${ }^{17}$

There are different degrees of severity of vesicoureteric reflux, and infants with gross reflux under the age of 1 year are those most at risk of developing renal parenchymal damage. ${ }^{18}$ Primary vesicoureteric reflux is an autosomal dominant congenital lesion with variable clinical expression, ${ }^{19}$ and early detection would permit early antimicrobial prophylaxis or corrective operation, or both. It is possible that routine renal ultrasonography after 28 weeks' gestation would detect some of the fetuses with severe vesicoureteric reflux, we found two in whom early treatment was possible.

Reflex nephropathy can have serious complications-such as hypertension-and was the principal diagnosis in $12 \%$ of the patients entering one dialysis and transplant programme. ${ }^{20}$ The capability of a general ultrasound screening programme to detect fetal urinary tract malformation has also been evaluated by Helin and Persson. ${ }^{15}$ They performed routine ultrasound examinations at 17 and 33 weeks' gestation, and almost all the renal abnormalities were found at the second examination. Our study confirms these results, and we suggest that all pregnant women should have a second routine ultrasound examination performed after 28 weeks' gestation to identify fetal malformations in the renal tract as well as growth and obstetric abnormalities.

This approach should be investigated further to delineate the natural progression of fetal renal tract abnormalities and to calculate the cost effectiveness of fetal screening in reducing late complications by early evaluation and treatment of asymptomatic neonates. ${ }^{19} 21$

\footnotetext{
References

1 Mendoza SA, Griswold WR, Leopold GR, Kaplan GW Intrauterine diagnosis of renal anomalies by ultrasonography. Am J Dis Child 1979;133:1042-3.
}

2 Birchall NM, Gunn TR, Mora JD, Mok PM. Diagnosis of unsuspected abdominal abnormalities by perinatal real-time ultrasound. NZ Med J 1982;720:818-9.

${ }^{3}$ Dell'Agnola CA, Tomaselli V, Ferrazzi E, Kustermann A, Nicolini U. Perinatal ultrasound monitoring: early detection and treatment of congenital uropathy. Br J Urol 1983;55:469-72.

4 Turnock RR, Shawis R. Management of fetal urinary tract anomalies detected by prenatal ultrasonography. Arch Dis Child 1984;59:962-5.

5 Gruenewald SM, Crocker EF, Walker AG, Trudinger BJ. Antenatal diagnosis of urinary tract abnormalities: correlation of ultrasound appearance with postnatal diagnosis. Am J Obstet Gynecol 1984;148:278-83.

6 Flake AW, Harrison MR, Sauer L, Adzick NS, de Lorimer AA. Ureteropelvic junction obstruction in the fetus. J Pediatr Surg 1986;21:1058-63.

7 Smith D, Egginton JA, Brookfield DSK. Detection of abnormality of fetal urinary tract as a predictor of renal tract disease. Br Med J 1987;294:27-8.

${ }^{8}$ Grignon A, Filion R, Filiatrault D, et al. Urinary tract dilation in utero: classification and clinical applications. Radiology 1986;160:645-7.

9 Grignon A, Filiatrault D, Homsy Y, et al. Ureteropelvic junction stenosis: antenatal ultrasonographic diagnosis, postnatal investigation and follow-up. Radiology 1986;160:649-51.

10 Arger PH, Coleman BG, Mintz MC, et al. Routine fetal genitourinary tract screening. Radiology 1985;156:485-9.

11 Mayor G, Genton N, Torrado A, Guignard J. Renal function in obstructive nephropathy: long term effect of reconstructive surgery. Pediatrics 1975;56:740-7.

12 Hobbins JC, Romero R, Grannum P, Berkowitz RL, Cullen M, Mahoney M. Antenatal diagnosis of renal anomalies with ultrasound. Obstructive uropathy. Am J Obstet Gynecol 1984;148:868-77.

${ }^{13}$ Nicolini U, Ferrazzi E, Kustermann A, et al. Perinatal management of fetal hydronephrosis with normal bladder. $J$ Perinat Med 1987;15:53-60.

${ }^{14}$ Campbell S, Wladimiroff JW, Dewhurst CJ. The antenatal measurement of fetal urine production. Journal of Obstetrics and Gynaecology of the British Commonwealth. 1973;80:680-6.

15 Helin I, Persson P. Prenatal diagnosis of urinary tract abnormalities by ultrasound. Pediatrics 1986;78:879-83.

16 Berkowitz RL, Glickman MG, Walker Smith GJ, et al. Fetal urinary tract obstruction: What is the role of surgical intervention in utero? Am J Obstet Gynecol 1982;144:367-75.

${ }^{17}$ Harrison MR, Golbus MS, Filly RA, et al. Fetal surgery for congenital hydronephrosis. N Engl J Med 1982;306:591-3.

18 Rolleston GL, Shannon FT, Utley WLF. Follow up of vesicoureteric reflux in the newborn. Kidney Int 1975;8:S59-64.

19 Chapman CJ, Bailey RR, Janus ED, Abbott GD, Lynn KL. Vesicoureteric reflux: segregation analysis. Am J Med Genet 1985;20:577-84.

${ }^{20}$ Olbing $\mathrm{H}$, Tamminen-Mobius $\mathrm{T}$. International reflux study patients with stable and unstable vesicoureterical reflux during preallocation period. Pediatric Nephrology 1987;1:W9-2.

21 Avni EF, Rodesch F, Schulman CC. Fetal uropathies: diagnostic pitfalls and management. J Urol 1985;134:921-4.

Correspondence to Dr TR Gunn, Paediatrician, St Helen's Hospital, Linwood Avenue, Auckland, New Zealand.

Accepted 29 February 1988 